\title{
Development of a self-management intervention to improve tamoxifen adherence in breast cancer survivors using an Intervention Mapping framework
}

Zoe Moon $^{1}$, Rona Moss-Morris ${ }^{1}$, Myra S. Hunter ${ }^{1}$, and Lyndsay D. Hughes ${ }^{1}$

${ }^{1}$ Health Psychology Section, Institute of Psychiatry, Psychology \& Neuroscience (IoPPN), King's College London, London, UK

Corresponding author at: Lyndsay D Hughes, Lyndsay.hughes@kcl.ac.uk, Health Psychology Section, King's College London, $5^{\text {th }}$ Floor Bermondsey Wing, Guy's Hospital, London, SE1 9RT. 


\title{
Development of a self-management intervention to improve tamoxifen adherence in breast cancer survivors using an Intervention Mapping framework
}

\begin{abstract}
Objective: Up to 50\% of women prescribed tamoxifen do not take it as prescribed for the full duration, which increases risk of recurrence and mortality. The current paper describes the development of a self-management intervention aiming to improve adherence in breast cancer survivors taking tamoxifen.
\end{abstract}

Methods: The intervention was developed following an Intervention Mapping approach. The content of the intervention was determined by theories of health behaviour and empirical evidence.

Development was an iterative process involving input from expert researchers, clinicians and patient representatives.

Results: The intervention was designed to improve both intentional and unintentional non-adherence. Key features included modifying unhelpful illness and treatment beliefs, improving confidence for coping with side effects and developing strategies for remembering to take tamoxifen.

Conclusion: Intervention Mapping proved a useful tool for developing an intervention which is grounded in theory and empirical evidence. The intervention has the potential to improve adherence in breast cancer survivors but needs to be trialled before the effectiveness of the intervention can be determined.

Practice implications: If shown to be effective, the intervention could be rolled out at a low cost to improve adherence and support breast cancer survivors prescribed tamoxifen. 


\section{Introduction}

Breast cancer is the most frequently diagnosed cancer and the leading cause of death in women, with over 1.6 million new cases a year worldwide [1]. Up to $75 \%$ of breast cancers are oestrogen receptor positive $(\mathrm{ER}+)$ where oestrogen stimulates cancers to replicate uncontrollably, forming tumours [2]. Women with ER+ early breast cancer are prescribed hormone therapy (HT) such as tamoxifen for up to ten years post primary treatment in order to reduce the risk of cancer recurrence. Tamoxifen works by blocking the effect of oestrogen on the cancer cells to reduce the likelihood that they develop into tumours. Studies show that taking tamoxifen for five years can reduce the risk of cancer recurrence by $50 \%$ [2] with further benefits when taken for an additional ten years [3].

However, by the fifth year of treatment, up to $50 \%$ of women have stopped taking their tamoxifen, known as non-persistence, or are not taking it as prescribed, known as non-adherence [4-6]. Due to the recent guideline changes increasing prescription from five to ten years, there are no studies measuring adherence and persistence at ten years but the persistent decline seen from year 1 to year 5 suggests that non-adherence is likely to be magnified by year 10. Both non-adherence and nonpersistence are associated with increased risk of recurrence and mortality [7, 8]. Therefore, there is a need to develop ways to improve adherence in this population to further improve long term survival. However, whilst there is increasing interest in identifying predictors or correlates of HT nonadherence, few studies have used the results to develop interventions, despite this being identified as a research priority [9]. This paper describes the development of an evidence-based and theory-driven self-management intervention to support women taking tamoxifen and improve adherence rates.

Across illnesses and medications, interventions to improve adherence tend to have little success [10, 11]. This is also true in HT adherence, where a number of studies have shown that providing educational materials to patients prescribed Aromatase Inhibitors (AIs), a similar class of drugs to tamoxifen, does not improve adherence rates [12-15]. However, there are several issues with the previous literature which may contribute to this lack of treatment efficacy. Firstly, the majority of previous interventions have not considered both intentional and unintentional non-adherence, a factor which may reduce effectiveness of adherence interventions [16]. Intentional non-adherence occurs when a patient makes a deliberate decision not to take medication as prescribed, whereas unintentional non-adherence occurs when a patient may forget to take their medication or they do not understand the instructions. Previous research in tamoxifen and HT adherence has demonstrated a distinction between factors which contribute to intentional and unintentional non-adherence, confirming the need to target these factors independently $[17,18]$. 
Secondly, many adherence interventions do not have a theoretical basis. Grounding interventions in theory is likely to improve their effectiveness by identifying theoretical constructs on which to focus the intervention, specifying effective behaviour change methods to address these constructs, and allowing evaluation of why improvements may have occurred $[16,19]$. Theory-based interventions also allow for study replication and reproducing interventions across different contexts or behaviours [20]. Finally, previous interventions often do not screen for non-adherence, and therefore include patients who are fully adherent $[21,22]$. This creates a ceiling effect, minimising the potential efficacy of the intervention by providing it to participants with no need for medication taking support [23]. This paper describes the development of an intervention to address tamoxifen non-adherence targeted at women with sub-optimal levels of adherence. Intervention development was based on two models of health behaviour which have been shown to explain tamoxifen non-adherence [18, 24]: the Common Sense Model of Illness Representations (CSM) and the Theory of Planned Behaviour (TPB), and both intentional and unintentional non-adherence were addressed.

\subsection{Framework for intervention development}

The intervention was developed in accordance with Medical Research Council (MRC) guidance for the development of complex interventions, which recommends that preliminary development work should be carried out prior to the commencement of any large RCT, and that interventions should be based on theory and empirical evidence to allow for replication and wide adoption of successful techniques [25]. Intervention Mapping (IM) was used as a framework for developing the intervention, as it provides a clear protocol for ensuring that interventions are grounded in theory [26].

\section{Method}

The IM framework involves a five-stage process: (1) needs assessment, (2) identifying intervention objectives and behavioural determinants, (3) selecting theory-based behaviour change methods, (4) organising the programme, (5) implementing and evaluating intervention (See Figure 1). This paper focusses on steps 1-4.

\subsection{Stage 1: Needs Assessment}

The first stage of IM involves carrying out a needs assessment to establish the extent of the health problem and identify determinants associated with the problem behaviour. This needs assessment was informed by a broad review of the literature, with reference to several systematic reviews [27-29]. In addition to this, the authors carried out a qualitative study and a longitudinal observational study to understand factors associated with non-adherence [30, 31]. 


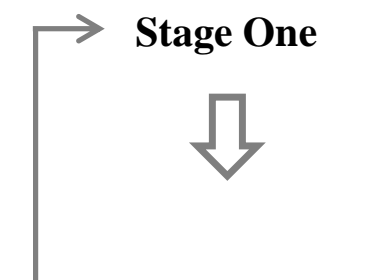

\author{
Stage Two

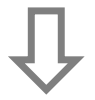 \\ Identity \\ Intervention \\ Objectives
}

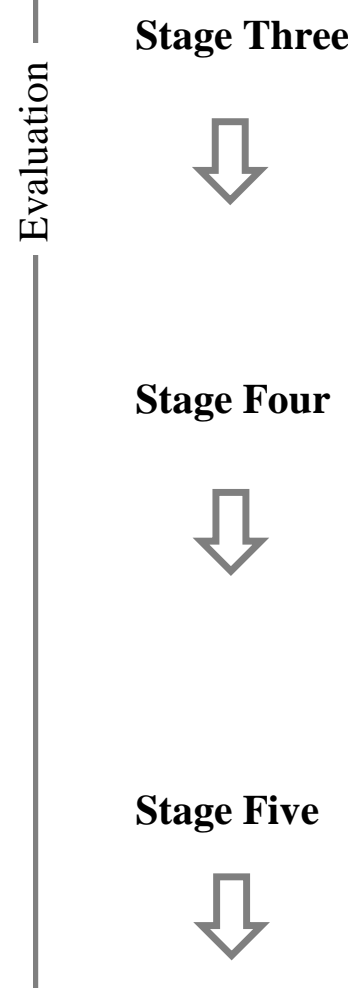

Needs

Assessment

Establish the extent of the problem

Identify behavioural and environmental determinants associated with the problem behaviour

Identify expected outcomes and performance objectives for intervention

Establish which behavioural determinants should be targeted

\section{Theory based methods and practical strategies}

Select or design practical applications to deliver change methods

Select theory and evidence based intervention methods based on preidentified determinants

\section{Integrate these practical applications into an organised programme}

Establish the format of the intervention

Draft and refine materials (consult with intended users)
Informed by

Literature review

Qualitative study of women prescribed tamoxifen [30]

Longitudinal study investigating predictors of non-adherence [31]

Needs Assessment (stage 1)

Theory of Planned Behaviour

Common-Sense Model

\section{Literature review}

Theory of Planned Behaviour

Common-Sense Model

COM-B

Cognitive Behaviour Therapy

Patient input

Clinicians

Research team

\section{Implementation}

\author{
Implementation Identify intended users \\ and evaluation Develop indicators and measures \\ for assessment \\ Evaluation plan
}

Figure 1. Adapted Interventon Mapping Framework

\subsection{Stage 2: Identify Intervention Objectives}

The next step of the IM process involves identifying the desired outcomes of the intervention.

Specific objectives related to improving adherence were specified, and these were broken down to determine the exact steps to improve adherence. This stage of the process allows researchers to be very clear and precise about what the intervention objectives are, and what determinants need to 
change in order to achieve these objectives. This stage was informed by the results of the needs assessment, and both the TPB and the CSM.

\subsection{Stage 3: Identify theory based methods and practical strategies}

The third stage involves identifying theory-based health behaviour change methods and techniques to map onto the determinants identified in the needs assessment. This was achieved through a thorough literature review.

\subsection{Stage 4: Develop intervention}

This stage of IM involves combining the information from all previous steps in order to develop the intervention program. The intervention was based on the determinants and behavioural strategies identified in the previous stages. The development was an iterative process and was informed by feedback from the research team and clinicians. Two nurse specialists reviewed the content of the intervention. In addition, as per recent guidance, patient representatives were involved in the development of the intervention from the very beginning [25, 32]. Interviews with three patient representatives took place before the intervention was developed in order to discuss the format and scope of the intervention. The intervention materials were then reviewed by nine patient representatives via email. These representatives were recruited through social media and were all breast cancer survivors prescribed tamoxifen.

\section{Results}

\subsection{Stage 1: Needs assessment}

The needs assessment highlighted the extent of non-adherence in this population, with adherence rates ranging from 47-97\% and falling over time (see [27, 28] for more detailed reviews). Unintentional non-adherence was reported much more frequently than intentional non-adherence and was associated with unique determinants $[17,18,31]$. Key barriers and facilitators of tamoxifen non-adherence identified by the needs assessment are shown in Table 1. More positive medication beliefs, such as higher necessity beliefs and lower concerns have consistently been associated with improved HT adherence and persistence [18, 31, 33-35]. Recent research has also highlighted the utility of illness perceptions, defined as the beliefs that patients hold about their illness, in understanding nonadherence to tamoxifen, a finding which has been supported across other conditions [36]. For example, women who perceived higher consequences of taking tamoxifen, who thought that their likelihood of cancer recurrence was low and believed that psychological stress would cause a 
recurrence were more likely to be non-adherent, whereas women who believed that health behaviours caused a recurrence were less likely to be non-adherent $[18,31]$.

Table 1. Key determinants of non-adherence (and non-persistence) identified by the needs assessment

\begin{tabular}{|c|c|c|}
\hline & Barrier to tamoxifen adherence & Facilitator of tamoxifen adherence \\
\hline Medication beliefs & $\begin{array}{l}\text { Concerns about medication }{ }^{[18,31,33]^{*}} \\
\text { Specific concerns (e.g. risk of endometrial } \\
\text { cancer) }\end{array}$ & Necessity beliefs $[18,33]^{*}[31,34,35]$ \\
\hline Illness perceptions & $\begin{array}{l}\text { Tamoxifen consequences }{ }^{[18]^{*}} \\
\text { Causal beliefs (psychological attributions) }{ }^{[18,31]^{*}}\end{array}$ & $\begin{array}{l}\text { Stronger beliefs in risk of recurrence }{ }^{[18]^{*}} \\
\text { Causal beliefs (health behaviours) }{ }^{[18]^{*}} \\
\text { Coherence }[31]\end{array}$ \\
\hline $\begin{array}{l}\text { Theory of planned } \\
\text { behaviour }\end{array}$ & - & $\begin{array}{l}\text { Positive attitude towards tamoxifen }{ }^{[31]} \\
\text { Self-efficacy for taking medication }{ }^{[17] \dagger}[79] \dagger^{*} \\
\text { Perceived behavioural control }\end{array}$ \\
\hline Side effects & $\begin{array}{l}\text { Number / intensity of side effect experience (e.g. } \\
\text { fatigue, vaginal dryness) }{ }^{[17,33]^{*}[7,31,39]}\end{array}$ & - \\
\hline Social support & - & $\begin{array}{l}\text { Perceived good social support }{ }^{[31,43-45]} \\
\text { Perceived self-efficacy in patient/doctor } \\
\text { relationship }{ }^{[80]}\end{array}$ \\
\hline Knowledge & Lack of information about treatment $[17,40,43]$ & $\begin{array}{l}\text { Information about treatment is } \\
\text { understandable }{ }^{[43]}\end{array}$ \\
\hline Distress & High levels of distress ${ }^{[31,46,81]}$ & - \\
\hline
\end{tabular}

From the Theory of Planned Behaviour, perceived behavioural control, which refers to the amount of control a patient feels they have over taking tamoxifen, and positive attitudes towards tamoxifen have been shown to be associated with increased adherence $[17,18,31]$.

As tamoxifen lowers circulating oestrogen levels, it is associated with menopausal related sideeffects, such as hot flushes, night sweats and loss of libido. These side-effects can have a significant impact on quality of life [37,38], and are often identified as drivers of non-adherence [7, 39]. Studies suggest that women often feel unprepared for the side-effects and that they are given little support in dealing with them [40, 41].Whilst the relationship between side-effects and adherence is not always consistent, qualitative research has shown that many women stop taking tamoxifen because of their side-effects $[30,42]$.

A range of studies have also identified lack of information as a barrier to tamoxifen adherence, with women who feel more informed about treatment being more likely to adhere [17, 40, 43, 44]. This is an important issue, as research has shown that many women report a lack of information provision or knowledge about tamoxifen [30, 40, 41]. Finally, low levels of social support and high levels of distress have also been identified as facilitators of non-adherence [31, 43, 45, 46]. 


\subsection{Stage 2: Identify Intervention Objectives}

The needs assessment identified that the intervention should aim to address both intentional and unintentional non-adherence, with a focus on unintentional non-adherence as this was reported more frequently. A number of determinants of adherence which may need to be modified in order to see improvements in adherence were also identified (see Table 1).

Modifying the following determinants formed part of the intervention objectives:

a) Increasing knowledge of, and beliefs about the necessity of, tamoxifen

b) Reducing concerns about tamoxifen

c) Reducing impact of side-effects

d) Increasing social support

e) Reducing likelihood patient will forget tamoxifen

f) Supporting development of accurate illness perceptions

Some of the factors in Table 1 overlap or map onto each other and can therefore be targeted together (Figure 2). For example, increasing knowledge should help to increase necessity beliefs and create more positive attitudes towards tamoxifen, which should also increase intentions to take tamoxifen [47-49]. Encouraging more accurate risk of recurrence perceptions may also increase necessity beliefs. Furthermore, women's concerns focus on side-effects, and therefore increasing women's confidence in managing these side-effects may help to reduce their concerns, resulting in a more favourable cost-benefit analysis.

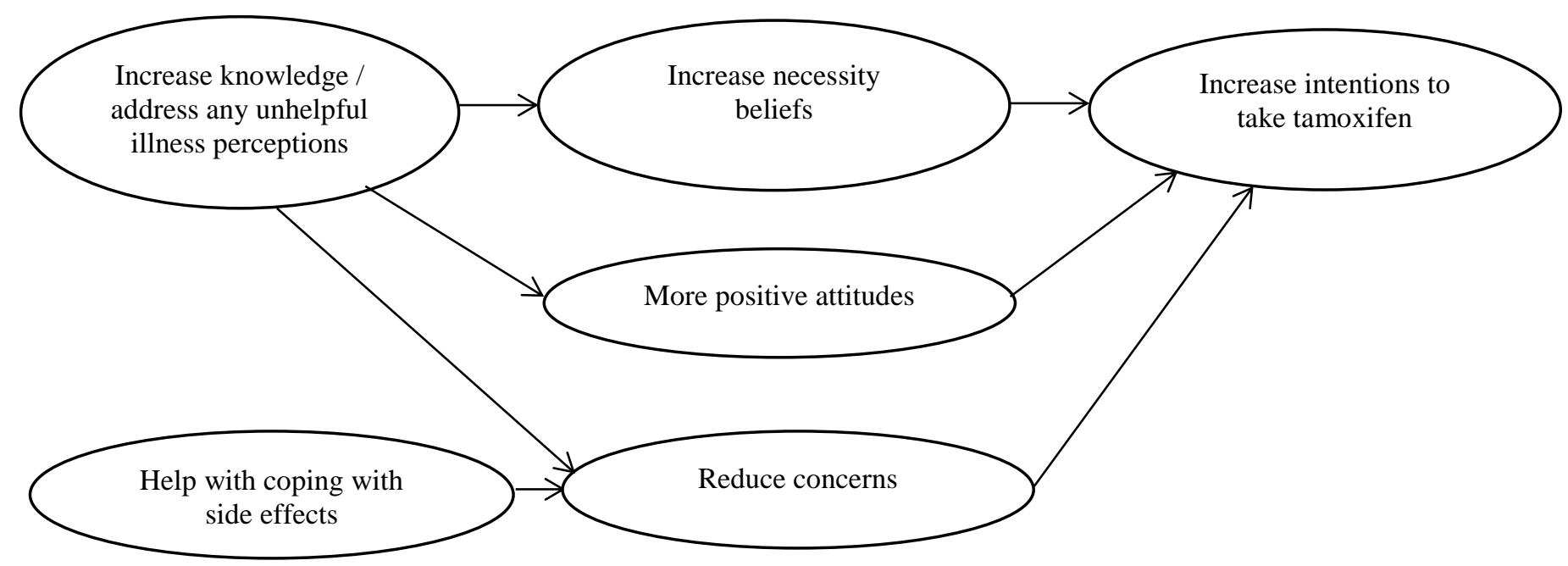

Figure 2. Theoretical interpretation of the inter-connectivity between key variables 
Table 2. Strategies for modifying key determinants associated with non-adherence

\begin{tabular}{llll}
\hline Key determinants & $\begin{array}{l}\text { General method for } \\
\text { addressing } \\
\text { determinant }\end{array}$ & Specific strategies / techniques & $\begin{array}{l}\text { Intervention } \\
\text { section }\end{array}$ \\
\hline
\end{tabular}

\begin{tabular}{|c|c|c|c|}
\hline \multirow[t]{3}{*}{ Medication beliefs } & $\begin{array}{l}\text { Increase necessity } \\
\text { beliefs }\end{array}$ & $\begin{array}{l}\text { Providing information on why tamoxifen is necessary, } \\
\text { how it works and what happens if doses are missed. } \\
\text { Visual information (diagrams) to demonstrate the } \\
\text { mode of action, quotes/videos for social comparison. }\end{array}$ & 1,2 \\
\hline & Address concerns & Providing information on common concerns. & $1,2,3$ \\
\hline & & $\begin{array}{l}\text { Activity to address concerns and challenge any } \\
\text { misconceptions of medication. }\end{array}$ & \\
\hline \multirow{3}{*}{ Illness perceptions } & $\begin{array}{l}\text { Challenge unhelpful } \\
\text { beliefs about illness }\end{array}$ & $\begin{array}{l}\text { Providing information on how tamoxifen works, how } \\
\text { effective is. }\end{array}$ & 1,2 \\
\hline & & Activity to challenge inaccurate beliefs. & \\
\hline & $\begin{array}{l}\text { Reduce tamoxifen } \\
\text { consequences }\end{array}$ & $\begin{array}{l}\text { Providing information on how to manage side effects. } \\
\text { Goal setting activity, videos and quotes for social } \\
\text { comparison. }\end{array}$ & 3 \\
\hline \multirow{3}{*}{$\begin{array}{l}\text { Theory of planned } \\
\text { behaviour constructs }\end{array}$} & $\begin{array}{l}\text { Increase intentions, } \\
\text { develop more positive } \\
\text { attitudes }\end{array}$ & $\begin{array}{l}\text { Providing information on how tamoxifen works, it's } \\
\text { effectiveness, consequences of not taking medication. } \\
\text { Addressing concerns associated with medication. }\end{array}$ & 1,2 \\
\hline & $\begin{array}{l}\text { Bridge gap between } \\
\text { intentions and } \\
\text { behaviour }\end{array}$ & $\begin{array}{l}\text { Implementation intentions activity, goal setting / } \\
\text { action planning, evaluation of goal setting. }\end{array}$ & 2 \\
\hline & $\begin{array}{l}\text { Improve perceived } \\
\text { behavioural control }\end{array}$ & $\begin{array}{l}\text { Tips for taking tamoxifen, social comparison, goal } \\
\text { setting/ action planning. }\end{array}$ & 2 \\
\hline \multirow{4}{*}{ Side effects } & $\begin{array}{l}\text { Develop coping skills } \\
\text { and enhance self- } \\
\text { efficacy }\end{array}$ & $\begin{array}{l}\text { Providing information on practical tips and coping } \\
\text { strategies for common side effects. Psychoeducation } \\
\text { on why side effects may occur. } \\
\text { Symptom monitoring, quotes and videos for social } \\
\text { comparison, enhance confidence for dealing with } \\
\text { symptoms. }\end{array}$ & 3 \\
\hline & $\begin{array}{l}\text { Set goals for } \\
\text { managing symptoms }\end{array}$ & $\begin{array}{l}\text { Formulate SMART goals, implement goals, evaluate } \\
\text { goal setting. }\end{array}$ & 3 \\
\hline & $\begin{array}{l}\text { Use CBT strategies to } \\
\text { help reduce impact of } \\
\text { HFNS }\end{array}$ & $\begin{array}{l}\text { Psychoeducation on the physiology of HFNS, identify } \\
\text { potential triggers, challenge negative thoughts about } \\
\text { HFNS, develop more helpful responses, } \\
\text { paced/diaphragmatic breathing. }\end{array}$ & 3 \\
\hline & $\begin{array}{l}\text { Use CBT strategies to } \\
\text { help reduce fatigue }\end{array}$ & $\begin{array}{l}\text { Psychoeducation on consequences of erratic patterns } \\
\text { of rest and activity/over-activity, importance of } \\
\text { establishing good sleep patterns and a balance of rest } \\
\text { and activity, challenge unhelpful thoughts and } \\
\text { behaviours which perpetuate fatigue, provision of } \\
\text { information on sleep hygiene. }\end{array}$ & 3 \\
\hline Social support & $\begin{array}{l}\text { Increase perceived } \\
\text { social support, } \\
\text { encourage women to } \\
\text { seek support }\end{array}$ & $\begin{array}{l}\text { Providing information on the importance of asking } \\
\text { for help, quotes and videos for social comparison. } \\
\text { Provide resources for seeking social support } \\
\text { elsewhere and for seeking professional help. }\end{array}$ & 4 \\
\hline
\end{tabular}




\begin{tabular}{llll}
\hline Knowledge & Information provision & $\begin{array}{l}\text { Psychoeducation, visual information, signposting to } \\
\text { further information, evaluation of knowledge. }\end{array}$ \\
\hline Forgetting & $\begin{array}{l}\text { Strategies to help } \\
\text { remember to take } \\
\text { tamoxifen, increase } \\
\text { motivation to } \\
\text { remember }\end{array}$ & $\begin{array}{l}\text { Practical tips, social comparison, implementation } \\
\text { intentions, information on consequences of non }- \\
\text { adherence }\end{array}$ \\
\hline
\end{tabular}

\subsection{Stage 3: Identify theory-based methods and practical strategies}

Many studies have suggested that improving the extent to which women feel informed about treatment should improve HT adherence rates [50, 51]. Providing information on the clinical benefits of tamoxifen is particularly important in a preventive medication like tamoxifen where the benefits are hidden, and where no reduction in symptoms can be attributed to medication taking [52]. This means there is no overt positive reinforcement for the patient to continue taking the medication. However, previous interventions to improve HT adherence have focussed mainly on providing information, and have been shown to be largely ineffective at improving adherence [53]. It has been suggested that the efficacy of interventions like these could be improved if combined with behavioural interventions or strategies to address medication beliefs $[53,54]$. Therefore, the current intervention included a range of different strategies and activities alongside information provision. The information presented was multi-modal, with written, visual and audio information, in order to cater to different learning needs [55]. Quotes and videos from other women were used throughout the intervention in an attempt to increase engagement. In addition to this, a range of evidence-based theories and strategies were used to increase the likelihood of behaviour change, including elements from Cognitive Behaviour Therapy (CBT) such as goal setting and cognitive reframing. These strategies are shown in Table 2 and are discussed below in relation to each of the key determinants associated with non-adherence.

Beliefs about tamoxifen, and to a lesser extent, beliefs about breast cancer, were identified as potential determinants of non-adherence in the needs assessment. As shown in Table 2, effective strategies to modify these beliefs include providing information to modify inaccurate perceptions, challenging unhelpful beliefs, discussing behaviour change methods and encouraging patients to generate responses to overcome their concerns [56-58]. Several studies have seen significant improvements in adherence rates following modification of illness and treatment perceptions [e.g. 57, 59]. Studies have also used diagrams or demonstrations of a medication's mode of action in order to modify treatment beliefs $[47,60]$. These help to turn intangible information into more concrete representations and can improve adherence rates [61,62]. As discussed above, this may be more effective than simply providing written information. 
Constructs from the TPB were identified as key determinants of non-adherence in Table 1 and techniques based on these constructs were integrated into the intervention (Table 2). Interventions based on this theory have shown success at improving adherence [63]. For example, several studies have successfully used implementation intentions, which involve pairing a critical cue (i.e. morning coffee) with the goal directed response (i.e. taking medication), thus establishing habit and removing the cognitive burden for patients to remember their medication [59, 64].

Another key determinant of non-adherence is side-effects. Research suggests that informing women which side-effects to expect and helping them to manage side-effects should improve adherence rates $[65,66]$. Several studies have shown that techniques such as providing clinical information on sideeffects, sharing experiences to empower patients, enhancing problem solving skills, cognitive reframing and relaxation can improve side effect management and quality of life [67-69]. CBT techniques have also shown success at improving symptom management, in patients with fatigue or with hot flushes and night sweats [70,71].

\subsection{Stage 4: Develop intervention}

Once the theory based methods and practical strategies were identified (Table 2), the format of the intervention programme was decided on. In this case, a self-management intervention was chosen as it was felt this would have the widest reach, especially in light of Open Access Follow Up being implemented for breast cancer survivors in the UK, meaning women have limited contact with their breast care team following primary treatment. Similar self-management interventions have been well received by patients and have improved a range of clinical and psychosocial outcomes [72, 73].

Patient representatives provided feedback on the format and scope of the intervention, agreeing that a self-management booklet would be helpful and appropriate. The overall feedback on the intervention materials was very positive, but some small changes were made based on patient feedback (Table 3). Constructive suggestions included reducing some repetitive information, and adding additional infographics and clinical information. Negative feedback tended to be focussed more around pragmatic issues, such as the use of the colour pink or the ordering of some information.

\subsection{Programme content}

The intervention booklet was split into four sections. Each of these sections included information, activities and quotes and videos from other breast cancer survivors. All patients read the first section (What is tamoxifen?), and then were directed to complete a questionnaire designed to highlight their particular areas of need. Patients then chose which of the following sections to focus on based on their tailored responses. 
Table 3. Feedback on the intervention materials from patient representatives

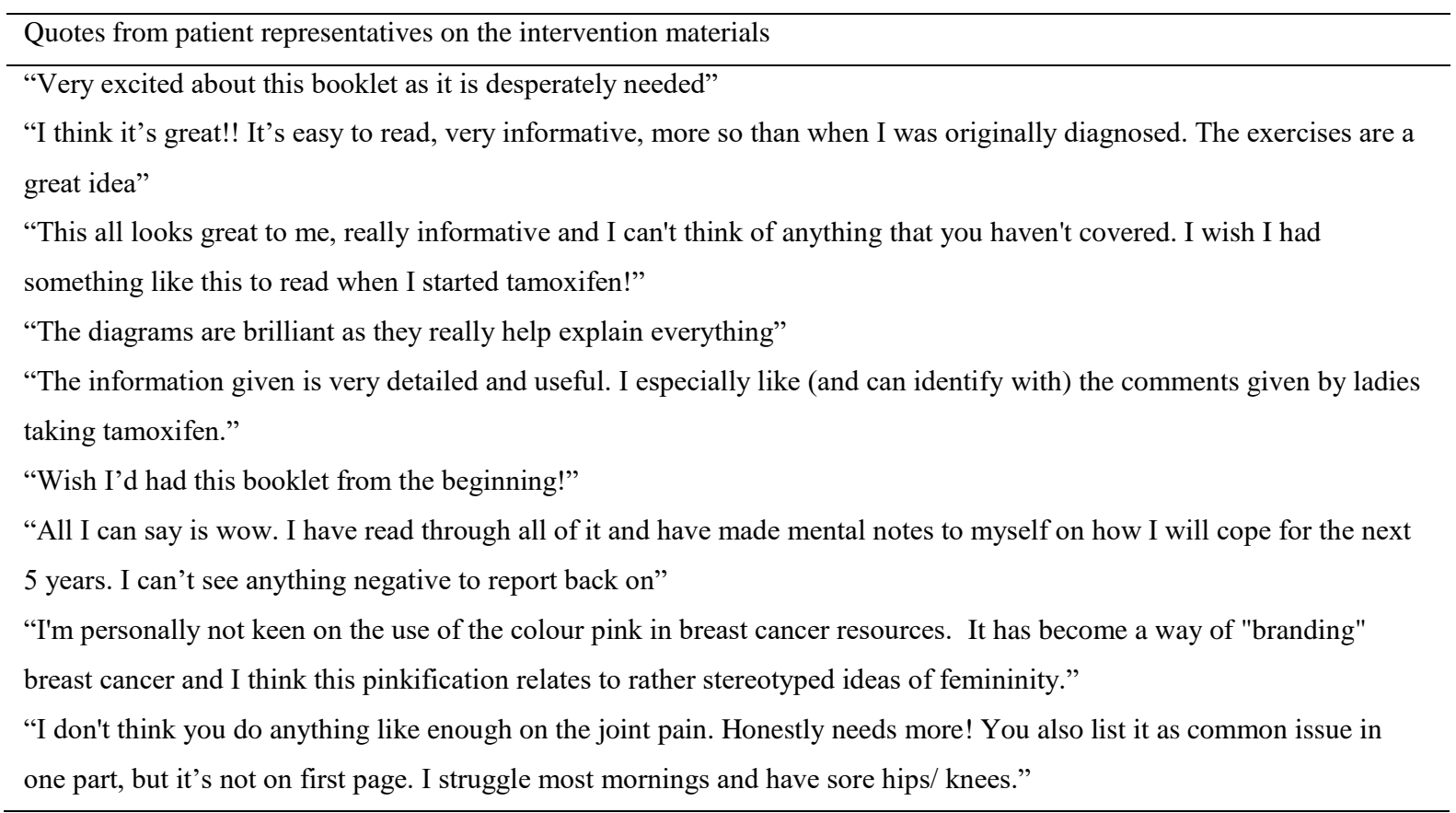

\subsubsection{Section one}

The first section of the booklet provides information on what tamoxifen is and how it works. To increase comprehension and in an attempt to modify medication beliefs, this section also includes diagrams to demonstrate how cancer cells can be stimulated and how tamoxifen can help to reduce this risk. Glossaries of key terms and signposting to sources of information are also included.

\subsubsection{Section 2}

Section two focuses on how to take tamoxifen and addresses both forgetting to take tamoxifen (unintentional non-adherence) and deliberately skipping doses (intentional non-adherence). The aim throughout this section is to educate patients on the importance of taking tamoxifen as prescribed, whilst normalising forgetting and understanding that for some women, non-adherence or nonpersistence may be the best solution based on their personalised risk of cancer recurrence and their quality of life. Some information from Section 1 is reiterated here, to explain what happens when doses are missed. Evidence suggests that some women who are non-adherent still feel they are appreciating the full clinical benefits of treatment [30]. Therefore, it was important to address this perception and provide more accurate information. To address unintentional non-adherence, women are given tips from other patients on remembering to take tamoxifen and how to improve planning. They are then encouraged to complete an implementation intentions activity, where they pair the behaviour of taking tamoxifen to a key activity in their day, such as a morning cup of coffee. Participants write their plan down in the template provided, visualise it and repeat it until they can 
recite it from memory. To address intentional non-adherence, information is provided to debunk five common concerns about tamoxifen. Women are then asked to list their personal concerns and then use problem solving to provide a response to overcome this concern.

\subsubsection{Section 3}

The third section focuses on how to manage common side-effects. Patients are introduced to the link between thoughts, feelings and behaviours, before completing a symptom monitoring diary to inform which symptoms to focus on. Information is then provided for six common side-effects: hot flushes and night sweats (HFNS), vaginal dryness/itchiness/discharge, tiredness/fatigue and insomnia, changes in mood, weight gain and joint pain. Each section includes information on why the side-effect may occur and tips for symptom management. After reading each section, patients are referred to an activity where they set a SMART goal to manage their symptoms. After spending two weeks implementing this goal, patients review their progress and make amendments to their goal if necessary. Examples are provided throughout to support women in trying new techniques.

The section on HFNS was informed by the successful CBT treatment for HFNS [70]. The sections on tiredness, fatigue and insomnia also utilise CBT techniques by reiterating the link between thoughts, feeling and behaviours and providing fatigue management techniques such as balancing rest and activity, keeping a fatigue diary and practising good sleep hygiene. The remaining sections provide a range of different tips for managing the symptoms, as well as quotes from breast cancer survivors and resources for more information or support. The aim of the section was not to remove the side-effects, as this is unlikely to be successful, but to improve women's confidence in coping with them and to reduce their impact on quality of life. Research has shown that non-adherence in haematological patients was linked not to frequency or presence of side-effects, but to the difficulty of handling sideeffects [74]. Furthermore, in breast cancer survivors, greater self-efficacy for coping with symptoms was associated with greater functional, emotional and social wellbeing after controlling for physical symptoms [75].

\subsubsection{Section 4}

The final section focuses on increasing access to social support, which was identified as a potential determinant of non-adherence. The section focuses on normalising the need for additional support and encouraging women to seek support from a range of sources. Resources are provided for finding helplines, support centres and face-to-face or online support groups. This section also addresses communication with healthcare professionals and encourages women to discuss their concerns with their healthcare team. 


\section{Discussion and conclusion}

\subsection{Discussion}

This paper describes the development of an intervention to improve adherence in breast cancer survivors taking tamoxifen. The intervention was developed following an iterative process involving feedback from researchers, clinicians and patients. The intervention aims to support breast cancer survivors with their tamoxifen treatment, by helping them to manage their side-effects, to remember to take the medication and to gain more understanding of how tamoxifen works. Preliminary feedback from patient representatives was positive, with women stating it was helpful and wishing it was available for them when they started treatment. The intervention has now been tested in a small pilot study which showed the intervention to be acceptable and feasible, with the potential to make significant improvements to adherence and a range of secondary outcomes, such as distress and quality of life [76].

This article meets the need for calls for more thorough descriptions of interventions, which are currently lacking [20,77], and which discuss not just what is included in the intervention, but why it is included [78]. This was achieved in the current paper by following the Intervention Mapping (IM) framework, which is a thorough and transparent method for developing interventions [26], allowing for very clear descriptions of how the intervention was developed, and showing the theoretical and empirical underpinnings of strategies used in the intervention. As well as following the IM framework, the intervention was based on two models of health behaviour (The Common Sense Model and the Theory of Planned Behaviour). These models were chosen as evidence has supported their use in understanding and predicting HT non-adherence $[18,24,31,79]$. Previous interventions to improve adherence are often not theoretically grounded or evidence based, which may contribute to the lack of efficacy seen across interventions $[16,19]$. The development was also in line with the MRC guidance for complex interventions, which states that interventions should be developed systematically based on the best available evidence and with theoretical understanding of the process of change [25]. Following guidelines and frameworks such as these increases the likelihood that the intervention will be effective [10].

Whilst the intervention was developed in a thorough and rigorous process, there are some limitations with the development process. The patient representatives in this study may have experienced some social desirability bias to please researchers, but this was overcome by collecting feedback over email and encouraging patients to be open and honest with their feedback. Furthermore, the patient representatives had no prior relationship with the research team. Strengths of the process include the breadth of evidence considered in the needs assessment, the use of evidence-based strategies for 
behaviour change and the input from patients and from a multidisciplinary team. Following the successful feasibility pilot study, the intervention now needs to be tested in a larger scale RCTs, as per the MRC guidance [25].

\subsection{Conclusions}

To our knowledge, this is the first intervention developed to improve tamoxifen adherence in breast cancer survivors prescribed tamoxifen. The intervention has been shown to be feasible and acceptable [76], however, the effectiveness of the intervention to improve adherence still needs to be tested in a fully powered RCT. Medication adherence is a complex behaviour and it is unclear if the current selfmanagement intervention is in depth or multi-faceted enough to change this behaviour. However, the self-management aspect increases the likelihood that the intervention can be implemented, as breast cancer survivors are increasingly being discharged from routine follow up and are being encouraged to self-manage.

\subsection{Practise implications}

In a small pilot study, the intervention has shown small to moderate size positive effects in adherence and a range of secondary outcomes including satisfaction with information about medication, illness and treatment beliefs, and self-efficacy in managing symptoms. As per the MRC guidance, an appbased version of this intervention is currently being tested in a larger scale randomised controlled trial to determine treatment efficacy. Due to the very large numbers of women with oestrogen receptor positive breast cancer being prescribed tamoxifen, this intervention has the potential to be rolled out widely, benefitting many women at a low cost.

\section{Acknowledgements}

Funding: This work was supported by funding from Breast Cancer Now (2013NovPhD201). 


\section{References}

[1] L.A. Torre, F. Bray, R.L. Siegel, L. Ferlay, J. Lortet-Tieulent, A. Jemal, Global Cancer Statistics, 2012, CA: A Cancer Journal for Clinicians, 65 (2015), 87-108. doi: 10.3322/caac.21262

[2] Early Breast Cancer Trialists' Collaborative Group, Tamoxifen for Early Breast Cancer: An Overview of the Randomised Trials, Lancet, 351 (1998), 1451-67.

[3] C. Davies, H. Pan, J. Godwin, R. Gray, R. Arriagada, V. Raina, M. Abraham, V.H. Medeiros Alencar, A. Badran, X. Bonfill, J. Bradbury, M. Clarke, R. Collins, S.R. Davis, A. Delmestri, J.F. Forbes, P. Haddad, M.F. Hou, M. Inbar, H. Khaled, J. Kielanowska, W.H. Kwan, B.S. Mathew, I. Mittra, B. Muller, A. Nicolucci, O. Peralta, F. Pernas, L. Petruzelka, T. Pienkowski, R. Radhika, B. Rajan, M.T. Rubach, S. Tort, G. Urrutia, M. Valentini, Y. Wang, R. Peto, Long-Term Effects of Continuing Adjuvant Tamoxifen to 10 Years Versus Stopping at 5 Years after Diagnosis of Oestrogen Receptor-Positive Breast Cancer: Atlas, a Randomised Trial, Lancet, 381 (2013), 805-16. doi: 10.1158/0008-5472.SABCS12-S1-2

[4] D.L. Hershman, L.H. Kushi, T. Shao, D. Buono, A. Kershenbaum, W.Y. Tsai, L. Fehrenbacher, S.L. Gomez, S. Miles, A.I. Neugut, Early Discontinuation and Nonadherence to Adjuvant Hormonal Therapy in a Cohort of 8,769 Early-Stage Breast Cancer Patients, J Clin Oncol, 28 (2010), 4120-8. . doi: 10.1200/JCO.2009.25.9655

[5] A.H. Partridge, P.S. Wang, E.P. Winer, J. Avorn, Nonadherence to Adjuvant Tamoxifen Therapy in Women with Primary Breast Cancer, J Clin Oncol, 21 (2003), 602-6. doi:

10.1200/JCO.2003.07.071

[6] M.P. van Herk-Sukel, L.V. van de Poll-Franse, A.C. Voogd, G.A. Nieuwenhuijzen, J.W. Coebergh, R.M. Herings, Half of Breast Cancer Patients Discontinue Tamoxifen and Any Endocrine Treatment before the End of the Recommended Treatment Period of 5 Years: A Population-Based Analysis, Breast Cancer Res Treat, 122 (2010), 843-51. doi: 10.1007/s10549-009-0724-3

[7] J.H. Chirgwin, A. Giobbie-Hurder, A.S. Coates, K.N. Price, B. Ejlertsen, M. Debled, R.D. Gelber, A. Goldhirsch, I. Smith, M. Rabaglio, J. F. Forbes, P. Neven, I. Lang, M. Colleoni, B. Thurlimann, Treatment Adherence and Its Impact on Disease-Free Survival in the Breast International Group 1-98 
Trial of Tamoxifen and Letrozole, Alone and in Sequence, J Clin Oncol, 34 (2016), 2452-9. doi: 10.1200/jco.2015.63.8619

[8] A.N. Winn, S.B. Dusetzina, The Association between Trajectories of Endocrine Therapy Adherence and Mortality among Women with Breast Cancer, Pharmacoepidemiol Drug Saf, 25 (2016), 953-9. doi: 10.1002/pds.4012

[9] S.A. Eccles, E.O. Aboagye, S. Ali, A.S. Anderson, J. Armes, F. Berditchevski, J. P. Blaydes, K. Brennan, N.J. Brown, H.E. Bryant, N.J. Bundred, J.M. Burchell, A.M. Campbell, J.S. Carroll,R.B. Clarke, C.E. Coles, G.J. Cook, A. Cox, N.J. Curtin, L.V. Dekker, S. Silva Idos, S.W. Duffy, D.F. Easton, D.M. Eccles, D.R. Edwards, J. Edwards, D. Evans, D.F. Fenlon, J.M. Flanagan, C. Foster, W.M. Gallagher, M. Garcia-Closas, J.M. Gee, A.J. Gescher, V. Goh, A.M. Groves, A.J. Harvey, M. Harvie, B.T. Hennessy, S. Hiscox, I. Holen, S.J. Howell, A. Howell, G. Hubbard, N. HulbertWilliams, M.S. Hunter, B. Jasani, L.J. Jones, T.J. Key, C.C. Kirwan, A. Kong, I.H. Kunkler, S.P. Langdon, M.O. Leach, D.J. Mann, J.F. Marshall, L. Martin, S.G. Martin, J.E. Macdougall, D.W. Miles, W.R. Miller, J.R. Morris, S.M. Moss, P. Mullan, R. Natrajan, J.P. O'Connor, R. O'Connor, C. Palmieri, P.D. Pharoah, E.A. Rakha, E. Reed, S.P. Robinson, E. Sahai, J.M. Saxton, P. Schmid, M.J. Smalley, V. Speirs, R. Stein, J. Stingl, C.H. Streuli, A.N. Tutt, G. Velikova, R.A. Walker, C.J. Watson, K.J. Williams, L.S. Young, A.M. Thompson, Critical Research Gaps and Translational Priorities for the Successful Prevention and Treatment of Breast Cancer, Breast Cancer Res, 15 (2013), R92.doi: 10.1186/bcr3493.

[10] R.B. Haynes, H. McDonald, A.X. Garg, and P. Montague, Interventions for Helping Patients to Follow Prescriptions for Medications, Cochrane Database Syst Rev (2002), CD000011. doi:

10.1200/JCO.2009.25.9655

[11] H.P. McDonald, A.X. Garg, R.B. Haynes, Interventions to Enhance Patient Adherence to Medication Prescriptions: Scientific Review, JAMA, 288 (2002), 2868-79. doi: 10.1001/jama.288.22.2868

[12] P. Hadji, M. Blettner, N. Harbeck, C. Jackisch, H.J. Luck, C. Windemuth-Kieselbach, S. Zaun, R. Kreienberg, The Patient's Anastrozole Compliance to Therapy (Pact) Program: A Randomized, inPractice Study on the Impact of a Standardized Information Program on Persistence and Compliance 
to Adjuvant Endocrine Therapy in Postmenopausal Women with Early Breast Cancer, Ann Oncol, 24 (2013), 1505-12. doi: 10.1093/annonc/mds653

[13] V. Ziller, I. Kyvernitakis, D. Knoll, A. Storch, O. Hars, P. Hadji, Influence of a Patient Information Program on Adherence and Persistence with an Aromatase Inhibitor in Breast Cancer Treatment--the Compas Study, BMC Cancer, 13 (2013), 407. doi: 10.1186/1471-2407-13-407 [14] K.D. Yu, Y. Zhou, G.Y. Liu, B. Li, P.Q. He, H.W. Zhang, L.H. Lou, X.J. Wang, S. Wang, J.H. Tang, Y.H. Liu, X. Wang, Z. F. Jiang, L.W. Ma, L. Gu, M.Z. Cao, Q.Y. Zhang, S.M. Wang, F.X. Su, H. Zheng, H.Y. Li, L. L. Tang, S.R. Sun, J.P. Liu, Z.M. Shao, Z.Z. Shen, A Prospective, Multicenter, Controlled, Observational Study to Evaluate the Efficacy of a Patient Support Program in Improving Patients' Persistence to Adjuvant Aromatase Inhibitor Medication for Postmenopausal, Early Stage Breast Cancer, Breast Cancer Res Treat, 134 (2012), 307-13 doi: 10.1007/s10549-012-2059-8 [15] P. Neven, C. Markopoulos, M. Tanner, M. Marty, R. Kreienberg, L. Atkins, A. Franquet, M. Gnant, S. Neciosup, P. Tesarova, S. Barni, V. Deschamp, The Impact of Educational Materials on Compliance and Persistence Rates with Adjuvant Aromatase Inhibitor Treatment: First-Year Results from the Compliance of Aromatase Inhibitors Assessment in Daily Practice through Educational Approach (Cariatide) Study, Breast, 23 (2014), 393-9. doi: 10.1016/j.breast.2014.02.009

[16] R. Horne, J. Weinman, N. Barber, R. Elliott, M. Morgan, A. Cribb, Concordance, Adherence and Compliance in Medicine Taking, London, 2005, pp. 40-46.

[17] H. Wouters, A.M. Stiggelbout, M.L. Bouvy, G.A. Maatman, E.C. Van Geffen, R. Vree, J.W. Nortier, L. Van Dijk, Endocrine Therapy for Breast Cancer: Assessing an Array of Women's Treatment Experiences and Perceptions, Their Perceived Self-Efficacy and Nonadherence, Clin Breast Cancer, 14 (2014), 460-67 e2. doi: doi: 10.1016/j.clbc.2014.04.005

[18] Z. Moon, R. Moss-Morris, M.S. Hunter, L.D. Hughes, More Than Just Side-Effects: The Role of Clinical and Psychosocial Factors in Non-Adherence to Tamoxifen, Br J Health Psychol, 22 (2017), 998-1018.doi: 10.1111/bjhp.12274.

[19] E.A. Holmes, D.A. Hughes, V.L. Morrison, Predicting Adherence to Medications Using Health Psychology Theories: A Systematic Review of 20 Years of Empirical Research, Value Health, 17 (2014), 863-76. doi: 10.1016/j.jval.2014.08.2671 
[20] S. Michie, M. Johnston, J. Francis, W. Hardeman, M. Eccles, From Theory to Intervention: Mapping Theoretically Derived Behavioural Determinants to Behaviour Change Techniques, Applied Psychology, 57 (2008), 660-80. doi: 10.1111/j.1464-0597.2008.00341.x

[21] R.A. Jeffery, T. Navarro, N.L. Wilczynski, E.C. Iserman, A. Keepanasseril, B. Sivaramalingam, T. Agoritsas, R.B. Haynes, Adherence Measurement and Patient Recruitment Methods Are Poor in Intervention Trials to Improve Patient Adherence, J Clin Epidemiol, 67 (2014), 1076-82 . doi: 10.1016/j.jclinepi.2014.06.008

[22] R. Nieuwlaat, N. Wilczynski, T. Navarro, N. Hobson, R. Jeffery, A. Keepanasseril, T. Agoritsas, N. Mistry, A. Iorio, S. Jack, Interventions for Enhancing Medication Adherence, The Cochrane Library (2014), CD000011. doi: 10.1002/14651858.CD000011.pub4

[23] T. Mathes, D. Pieper, S.L. Antoine, M. Eikermann, Adherence Influencing Factors in Patients Taking Oral Anticancer Agents: A Systematic Review, Cancer Epidemiol, 38 (2014), 214-26. doi: 10.1016/j.ctrv.2013.07.004

[24] A.L. Corter, R. Broom, D. Porter, V. Harvey, M. Findlay, Predicting Nonadherence to Adjuvant Endocrine Therapy in Women with Early Stage Breast Cancer, Psychooncology (2018). doi: $10.1002 /$ pon. 4771

[25] P. Craig, P. Dieppe, S. Macintyre, S. Michie, I. Nazareth, M. Petticrew, Developing and Evaluating Complex Interventions: The New Medical Research Council Guidance, BMJ, 337 (2008), a1655.

[26] G. Kok, N.H. Gottlieb, G.J. Peters, P.D. Mullen, G.S. Parcel, R.A. Ruiter, M.E. Fernandez, C. Markham, L.K. Bartholomew, A Taxonomy of Behaviour Change Methods: An Intervention Mapping Approach, Health Psychol Rev, 10 (2016), 297-312. doi: 10.1080/17437199.2015.1077155

[27] C.C. Murphy, L.K. Bartholomew, M.Y. Carpentier, S.M. Bluethmann, S.W. Vernon, Adherence to Adjuvant Hormonal Therapy among Breast Cancer Survivors in Clinical Practice: A Systematic Review, Breast Cancer Res Treat, 134 (2012), 459-78. doi: 10.1007/s10549-012-2114-5 [28] Z. Moon, R. Moss-Morris, M.S. Hunter, S. Carlisle, L.D. Hughes, Barriers and Facilitators of Adjuvant Hormone Therapy Adherence and Persistence in Women with Breast Cancer: A Systematic Review, Patient Prefer Adherence, 11 (2017), 305-22. doi: 10.2147/ppa.s126651 
[29] C. Lin, R. Clark, P. Tu, H.B. Bosworth, and L.L. Zullig, Breast Cancer Oral Anti-Cancer Medication Adherence: A Systematic Review of Psychosocial Motivators and Barriers, Breast Cancer Res Treat, 165 (2017), 247-60. doi: 10.1007/s10549-017-4317-2

[30] Z. Moon, R. Moss-Morris, M.S. Hunter L.D. Hughes,Understanding Tamoxifen Adherence in Women with Breast Cancer: A Qualitative Study, Br J Health Psychol, 22 (2017), 978-97. doi: 10.1111/bjhp.12266

[31] Z. Moon, R. Moss-Morris, M.S. Hunter, S. Norton, L.D. Hughes, Non-Adherence to Tamoxifen in Breast Cancer Survivors: A 12 Month Longitudinal Analysis, Health Psychology (2019), Early Online View, DOI: 10.1037/hea0000785,

[32] L. Yardley, L. Morrison, K. Bradbury, and I. Muller, The Person-Based Approach to Intervention Development: Application to Digital Health-Related Behavior Change Interventions, J Med Internet Res, 17 (2015), e30. doi: 10.2196/jmir.4055

[33] J. Brett, D. Fenlon, M. Boulton, N.J. Hulbert-Williams, F.M. Walter, P. Donnelly, B. Lavery, A. Morgan, C. Morris, E. Watson, Factors Associated with Intentional and Unintentional NonAdherence to Adjuvant Endocrine Therapy Following Breast Cancer, Eur J Cancer Care (Engl), 27 (2018). doi/10.1111/ecc.12601/abstract

[34] K.R. Jacob Arriola, T.A. Mason, K.A. Bannon, C. Holmes, C.L. Powell, K. Horne, R.O'Regan, Modifiable Risk Factors for Adherence to Adjuvant Endocrine Therapy among Breast Cancer Patients, Patient Educ Couns, 95 (2014), 98-103. doi: 10.1016/j.pec.2013.12.019

[35] A.L. Stanton, K.J. Petrie, A.H. Partridge, Contributors to Nonadherence and Nonpersistence with Endocrine Therapy in Breast Cancer Survivors Recruited from an Online Research Registry, Breast Cancer Res Treat, 145 (2014), 525-34. doi: 10.1007/s10549-014-2961-3

[36] R. Horne, J. Weinman, Self-Regulation and Self-Management in Asthma: Exploring the Role of Illness Perceptions and Treatment Beliefs in Explaining Non-Adherence to Preventer Medication, Psychology \& Health, 17 (2002), 17-32. doi: 10.1080/08870440290001502

[37] J.R. Garreau, T. Delamelena, D. Walts, K. Karamlou, N. Johnson, Side Effects of Aromatase Inhibitors Versus Tamoxifen: The Patients' Perspective, Am J Surg, 192 (2006), 496-8. doi: 10.1016/j.amjsurg.2006.06.018 
[38] D.U. Boehm, A. Lebrecht, T. Eckhardt, S. Albrich, M. Schmidt, W. Siggelkow, E. Kandelhardt, H. Koelbl, Quality of Life and Adjuvant Tamoxifen Treatment in Breast Cancer Patients, Eur J Cancer Care (Engl), 18 (2009), 500-6. doi: 10.1111/j.1365-2354.2008.01015.x

[39] S.A. Doggrell, Adherence to Oral Endocrine Treatments in Women with Breast Cancer: Can It Be Improved?, Breast Cancer Res Treat, 129 (2011), 299-308. doi: 10.1007/s10549-011-1578-z [40] P. Wuensch, A. Hahne, R. Haidinger, K. Meissler, B. Tenter, C. Stoll, B. Senf, J.Huebner, Discontinuation and Non-Adherence to Endocrine Therapy in Breast Cancer Patients: Is Lack of Communication the Decisive Factor?, J Cancer Res Clin Oncol, 141 (2015), 55-60. doi: $10.1007 / \mathrm{s} 00432-014-1779-\mathrm{z}$

[41] G.J. van Londen, H.S. Donovan, E.B. Beckjord, A.L. Cardy, D.H. Bovbjerg, N.E. Davidson, J.Q. Morse, G.E. Switzer, I.M. Verdonck-de Leeuw, M.A. Dew, Perspectives of Postmenopausal Breast Cancer Survivors on Adjuvant Endocrine Therapy-Related Symptoms, Oncol Nurs Forum, 41 (2014), 660-8. doi: 10.1188/14.onf.660-668

[42] K.J. Wells, T.M. Pan, C. Vazquez-Otero, D. Ung, A.E. Ustjanauskas, D. Munoz, C. Laronga, R.G. Roetzheim, M. Goldenstein, C. Carrizosa, S. Nuhaily, K. Johnson, M. Norton, E. Sims, G.P. Quinn, Barriers and Facilitators to Endocrine Therapy Adherence among Underserved HormoneReceptor-Positive Breast Cancer Survivors: A Qualitative Study, Support Care Cancer, 24 (2016), 4123-30. doi: doi: 10.1007/s00520-016-3229-8

[43] C. Cluze, D. Rey, L. Huiart, M.K. BenDiane, A.D. Bouhnik, C. Berenger, M.P. Carrieri, R. Giorgi, Adjuvant Endocrine Therapy with Tamoxifen in Young Women with Breast Cancer: Determinants of Interruptions Vary over Time, Ann Oncol, 23 (2012), 882-90. doi: 10.1093/annonc/mdr330

[44] V.B. Sheppard, L.A. Faul, G. Luta, J.D. Clapp, R.L. Yung, J.H. Wang, G. Kimmick, C. Isaacs, M. Tallarico, W.T. Barry, B N. Pitcher, C. Hudis, E.P. Winer, H.J. Cohen, H.B. Muss, A. Hurria, J.S. Mandelblatt, Frailty and Adherence to Adjuvant Hormonal Therapy in Older Women with Breast Cancer: Calgb Protocol 369901, J Clin Oncol, 32 (2014), 2318-27. doi: 10.1200/JCO.2013.51.7367 
[45] L. Huiart, A.D. Bouhnik, D. Rey, C. Tarpin, C. Cluze, M.K. Bendiane, P. Viens, R. Giorgi, Early Discontinuation of Tamoxifen Intake in Younger Women with Breast Cancer: Is It Time to Rethink the Way It Is Prescribed?, Eur J Cancer, 48 (2012), 1939-46. doi: 10.1016/j.ejca.2012.03.004 [46] R.L. Sedjo, S. Devine, Predictors of Non-Adherence to Aromatase Inhibitors among Commercially Insured Women with Breast Cancer, Breast Cancer Res Treat, 125 (2011), 191-200. doi: 10.1007/s10549-010-0952-6

[47] A.S. Jones, C.J. Ellis, M. Nash, B. Stanfield, E. Broadbent, Using Animation to Improve Recovery from Acute Coronary Syndrome: A Randomized Trial, Ann Behav Med, 50 (2016), 108-18 doi: 10.1007/s12160-015-9736-x

[48] B.G. Bender, A. Apter, D.K. Bogen, P. Dickinson, L. Fisher, F.S Wamboldt, J.M. Westfall, Test of an Interactive Voice Response Intervention to Improve Adherence to Controller Medications in Adults with Asthma, J Am Board Fam Med, 23 (2010), 159-65. doi: 10.3122/jabfm.2010.02.090112 [49] R.E. O'Carroll, J.A. Chambers, M. Dennis, C. Sudlow, M. Johnston, Improving Medication Adherence in Stroke Survivors: Mediators and Moderators of Treatment Effects, Health Psychol, 33 (2014), 1241-50. doi: 10.1037/hea0000082

[50] A.K. Fink, J. Gurwitz, W. Rakowski, E. Guadagnoli, R.A. Silliman, Patient Beliefs and Tamoxifen Discontinuance in Older Women with Estrogen Receptor--Positive Breast Cancer, J Clin Oncol, 22 (2004), 3309-15. doi: 10.1200/JCO.2004.11.064

[51] H.J. Burstein, C. Lacchetti, J.J. Griggs, Adjuvant Endocrine Therapy for Women with Hormone Receptor-Positive Breast Cancer: American Society of Clinical Oncology Clinical Practice Guideline Update on Ovarian Suppression Summary, J Clin Oncol, 34 (2016), 1689-701. doi:

10.1200/JCO.2015.65.9573.

[52] D. Meyer, H. Leventhal, M. Gutmann, Common-Sense Models of Illness: The Example of Hypertension, Health Psychol, 4 (1985), 115-35.

[53] A. Hurtado-de-Mendoza, M.L. Cabling, T. Lobo, C. Dash, V.B. Sheppard, Behavioral Interventions to Enhance Adherence to Hormone Therapy in Breast Cancer Survivors: A Systematic Literature Review, Clin Breast Cancer, 16 (2016), 247-55. doi: 10.1016/j.clbc.2016.03.006. 
[54] E. Costa, A. Giardini, M. Savin, E. Menditto, E. Lehane, O. Laosa, S. Pecorelli, A. Monaco, A. Marengoni, Interventional Tools to Improve Medication Adherence: Review of Literature, Patient Prefer Adherence, 9 (2015), 1303-14. doi: 10.2147/PPA.S87551

[55] J.H. Jones, L.A. Treiber, M.C. Jones, Intervening at the Intersection of Medication Adherence and Health Literacy, The Journal for Nurse Practitioners, 10 (2014), 527-34. doi:

10.1016/j.nurpra.2014.06.014

[56] E. Broadbent, C.J. Ellis, J. Thomas, G. Gamble, and K.J. Petrie, Further Development of an Illness Perception Intervention for Myocardial Infarction Patients: A Randomized Controlled Trial, J Psychosom Res, 67 (2009), 17-23. doi: 10.1016/j.jpsychores.2008.12.001

[57] K.J. Petrie, K. Perry, E. Broadbent, J. Weinman, A Text Message Programme Designed to Modify Patients' Illness and Treatment Beliefs Improves Self-Reported Adherence to Asthma Preventer Medication, Br J Health Psychol, 17 (2012), 74-84. doi: 10.1111/j.2044-8287.2011.02033.x [58] M. Glattacker, K. Heyduck, C. Meffert, Illness Beliefs, Treatment Beliefs and Information Needs as Starting Points for Patient Information--Evaluation of an Intervention for Patients with Chronic Back Pain, Patient Educ Couns, 86 (2012), 378-89. doi: 10.1016/j.pec.2011.05.028

[59] R.E. O'Carroll, J.A. Chambers, M. Dennis, C. Sudlow, M. Johnston, Improving Adherence to Medication in Stroke Survivors: A Pilot Randomised Controlled Trial, Ann Behav Med, 46 (2013), 358-68. doi: 10.1007/s12160-013-9515-5

[60] C. Karamanidou, J. Weinman, R. Horne, Improving Haemodialysis Patients' Understanding of Phosphate-Binding Medication: A Pilot Study of a Psycho-Educational Intervention Designed to Change Patients' Perceptions of the Problem and Treatment, Br J Health Psychol, 13 (2008), 205-14. doi: $10.1348 / 135910708 \times 288792$

[61] Y. El Miedany, M. El Gaafary, D. Palmer, Assessment of the Utility of Visual Feedback in the Treatment of Early Rheumatoid Arthritis Patients: A Pilot Study, Rheumatol Int, 32 (2012), 3061-8. doi: 10.1007/s00296-011-2098-1

[62] A.S. Jones, and K.J. Petrie, I Can See Clearly Now: Using Active Visualisation to Improve Adherence to Art and Prep, AIDS Behav, 21 (2017), 335-40. doi: 10.1007/s10461-016-1611-7 
[63] G.N. Bai, Y.F. Wang, L. Yang, W.Y. Niu, Effectiveness of a Focused, Brief Psychoeducation Program for Parents of Adhd Children: Improvement of Medication Adherence and Symptoms, Neuropsychiatr Dis Treat, 11 (2015), 2721-35. doi: https://doi.org/10.2147/NDT.S88625

[64] T.L. Webb, P. Sheeran, Does Changing Behavioral Intentions Engender Behavior Change? A Meta-Analysis of the Experimental Evidence, Psychol Bull, 132 (2006), 249. doi: 10.1037/00332909.132.2.249

[65] L. Wood, A Review on Adherence Management in Patients on Oral Cancer Therapies, Eur J Oncol Nurs, 16 (2012), 432-8. doi: 10.1016/j.ejon.2011.10.002

[66] L. Fallowfield, There's Many a Slip Twixt Cup and Lip: Adherence Issues in Cancer Therapy, Nat Clin Pract Oncol, 5 (2008), 118-9. doi: 10.1038/ncponc1043

[67] T.A. Badger, C.J. Braden, M.H. Mishel, Depression Burden, Self-Help Interventions, and Side Effect Experience in Women Receiving Treatment for Breast Cancer, Oncol Nurs Forum, 28 (2001), $567-74$.

[68] F. Gaston-Johansson, J.M. Fall-Dickson, J.P. Nanda, E.K. Sarenmalm, M. Browall, N. Goldstein, Long-Term Effect of the Self-Management Comprehensive Coping Strategy Program on Quality of Life in Patients with Breast Cancer Treated with High-Dose Chemotherapy, Psychooncology, 22 (2013), 530-9. doi: 10.1002/pon.3031

[69] M. Golant, T. Altman, C. Martin, Managing Cancer Side Effects to Improve Quality of Life: A Cancer Psychoeducation Program, Cancer Nurs, 26 (2003), 37-44; quiz 45-6.

[70] E. Mann, M.J. Smith, J. Hellier, J.A. Balabanovic, H. Hamed, E.A. Grunfeld, M.S. Hunter, Cognitive Behavioural Treatment for Women Who Have Menopausal Symptoms after Breast Cancer Treatment (Menos 1): A Randomised Controlled Trial, Lancet Oncol, 13 (2012), 309-18. doi: 10.1016/s1470-2045(11)70364-3

[71] R. Moss-Morris, P. McCrone, L. Yardley, K. van Kessel, G. Wills, L. Dennison, A Pilot Randomised Controlled Trial of an Internet-Based Cognitive Behavioural Therapy Self-Management Programme (Ms Invigor8) for Multiple Sclerosis Fatigue, Behav Res Ther, 50 (2012), 415-21. doi: 10.1016/j.brat.2012.03.001 
[72] L. Coffey, O. Mooney, S. Dunne, L. Sharp, A. Timmons, D. Desmond, E. O'Sullivan, C. Timon,

R. Gooberman-Hill, P. Gallagher, Cancer Survivors' Perspectives on Adjustment-Focused SelfManagement Interventions: A Qualitative Meta-Synthesis, J Cancer Surviv, 10 (2016), 1012-34. doi: $10.1007 / \mathrm{s} 11764-016-0546-3$

[73] J. Goldberg, J. Hinchey, S. Feder, D. Schulman-Green, Developing and Evaluating a SelfManagement Intervention for Women with Breast Cancer, West J Nurs Res, 38 (2016), 1243-63. doi: $10.1177 / 0193945916650675$

[74] J.L. Richardson, G. Marks, A. Levine, The Influence of Symptoms of Disease and Side Effects of Treatment on Compliance with Cancer Therapy, J Clin Oncol, 6 (1988), 1746-52.

[75] R.A. Shelby, S.N. Edmond, A.A. Wren, F.J. Keefe, J.M. Peppercorn, P.K. Marcom, K.L. Blackwell, G.G. Kimmick, Self-Efficacy for Coping with Symptoms Moderates the Relationship between Physical Symptoms and Well-Being in Breast Cancer Survivors Taking Adjuvant Endocrine Therapy, Support Care Cancer, 22 (2014), 2851-9. doi: 10.1007/s00520-014-2269-1

[76] Z. Moon, R. Moss-Morris, M.S. Hunter, S. Goodliffe, L.D. Hughes, Acceptability and feasibility of a self-management intervention for women prescribed tamoxifen, Health Education Journal, Online Early View (2019). doi:10.1177/0017896919853856

[77] S.U. Dombrowski, F.F. Sniehotta, A. Avenell, and J.C. Coyne, Current Issues and Future Directions in Psychology and Health: Towards a Cumulative Science of Behaviour Change: Do Current Conduct and Reporting of Behavioural Interventions Fall Short of Best Practice?, Psychol Health, 22 (2007), 869-874. doi: 10.1080/08870440701520973

[78] H. Schaalma, G. Kok, Decoding Health Education Interventions: The Times Are a-Changin', Psychol Health, 24 (2009), 5-9. doi: 10.1080/08870440903126348.

[79] G. Kimmick, S.N. Edmond, H.B. Bosworth, J. Peppercorn, P.K. Marcom, K. Blackwell, F.J. Keefe, R.A. Shelby, Medication Taking Behaviors among Breast Cancer Patients on Adjuvant Endocrine Therapy, The Breast, 24 (2015), 630-36. doi: 10.1016/j.breast.2015.06.01 [80] Y.Liu, J.L. Malin, A.L. Diamant, A. Thind, R.C. Maly, Adherence to Adjuvant Hormone Therapy in Low-Income Women with Breast Cancer: The Role of Provider-Patient Communication, Breast Cancer Res Treat, 137 (2013), 829-36. doi: 10.1007/s10549-012-2387-8 
[81] C.M. Bender, A.L. Gentry, A.M. Brufsky, F.E. Casillo, S.M. Cohen, M.M. Dailey, H.S.

Donovan, J. Dunbar-Jacob, R.C. Jankowitz, M.Q. Rosenzweig, P.R. Sherwood, S.M. Sereika,

Influence of Patient and Treatment Factors on Adherence to Adjuvant Endocrine Therapy in Breast

Cancer, Oncol Nurs Forum, 41 (2014), 274-85. doi: 10.1188/14.ONF.274-28 